\title{
Optimized Production of Poly( $\gamma$-Glutamic acid) By Bacillus sp. FBL-2 through Response Surface Methodology Using Central Composite Design
}

\author{
Ju-Hee Min $^{1 \dagger}$, Lebaka Veeranjaneya Reddy ${ }^{1,2 \dagger}$, Dimitris Charalampopoulos ${ }^{3}$, Young-Min Kim ${ }^{4 *}$, and \\ Young-Jung Wee ${ }^{1 *}$ \\ ${ }^{1}$ Department of Food Science and Technology, Yeungnam University, Gyeongsan 38541, Republic of Korea \\ ${ }^{2}$ Department of Microbiology, Yogi Vemana University, Kadapa (A.P.) 516003 , India \\ ${ }^{3}$ Department of Food and Nutritional Sciences, University of Reading, Whiteknights, PO Box 226, Reading RG6 6AP, UK \\ ${ }^{4}$ Department of Food Science and Technology, Chonnam National University, Gwangju 61186, Republic of Korea
}

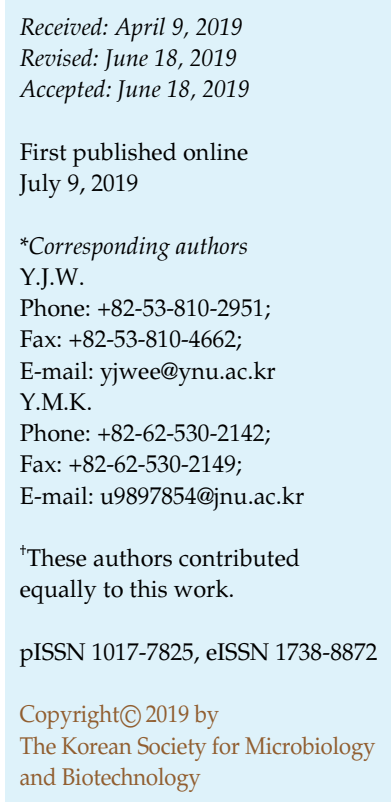

In the present study, the optimization of $\operatorname{poly}(\gamma$-glutamic acid) $(\gamma$-PGA) production by Bacillus sp. FBL-2 was studied using a statistical approach. One-factor-at-a-time method was used to investigate the effect of carbon sources and nitrogen sources on $\gamma$-PGA production and was utilized to select the most significant nutrients affecting the yield of $\gamma$-PGA. After identifying effective nutrients, response surface methodology with central composite design (CCD) was used to obtain a mathematical model to identify the optimum concentrations of the key nutrients (sucrose, L-glutamic acid, yeast extract, and citric acid) for improvement of $\gamma$-PGA production. The optimum amount of significant medium components appeared to be sucrose $51.73 \mathrm{~g} / \mathrm{l}$, L-glutamic acid $105.30 \mathrm{~g} / \mathrm{l}$, yeast extract $13.25 \mathrm{~g} / \mathrm{l}$, and citric acid $10.04 \mathrm{~g} / \mathrm{l}$. The optimized medium was validated experimentally, and $\gamma$-PGA production increased significantly from $3.59 \mathrm{~g} / 1(0.33 \mathrm{~g} / \mathrm{l} / \mathrm{h})$ to $44.04 \mathrm{~g} / 1(3.67 \mathrm{~g} / \mathrm{l} / \mathrm{h})$ when strain FBL-2 was cultivated under the optimal medium developed by the statistical approach, as compared to non-optimized medium.

Keywords: Poly( $\gamma$-glutamic acid), L-glutamic acid, Bacillus sp. FBL-2, optimization, response surface methodology

\section{Introduction}

Poly $(\gamma$-glutamic acid) $(\gamma$-PGA $)$ is an interesting biodegradable homopolyamide that is composed of $\mathrm{D}$ - and L-glutamic acid residues [1]. Although there are two types of PGA ( $\alpha$ and $\gamma$ forms), it is easier to produce $\gamma$-PGA than a-PGA by bacterial fermentation using Bacillus sp. [2]. $\gamma$ PGA is resistant to proteases as glutamate is usually polymerized into $\gamma$-PGA via the $\gamma$-amide linkages inside the bacterial cell [3]. The $\gamma$-PGA properties like water solubility, non-toxicity, edibility, thickening capacity, metal binding, good absorbability, and biodegradability provide for its usage as a drug carrier [4-6], an antifreeze agent, a food thickener [7-9], a flocculating agent for environmental protection, and as a humectant in cosmetics $[10,11]$. All the above-mentioned properties and applications of $\gamma$-PGA are attracting present-day investigators to study high-yield production strategies.

$\gamma$-PGA can be produced through four different chemical and biological methods: chemical synthesis, peptide synthesis, biotransformation, and microbial fermentation [12]. However, $\gamma$-PGA production through microbial fermentation is considered economical and it has some advantages such as inexpensive raw materials, minimal environmental pollution, high natural product purity, and mild reaction conditions when compared with other methods. Ivanovics and Bruckner first discovered $\gamma$-PGA from a capsule of Bacillus anthracis [13]. Afterwards it was 
identified in archaea, bacteria, and eukaryotes. Apart from all other organisms and genera, Bacillus is very popular for use in $\gamma$-PGA production through fermentation. Bacillus strains can be classified into two major groups based on the requirement of L-glutamic acid as a carbon and nitrogen source for $\gamma$-PGA production and cell growth. L-Glutamatedependent strains (such as B. licheniformis ATCC 9945a, B. subtilis IFO3335, B. subtilis F-2-01, Bacillus sp. RKY3) are known to produce high levels of $\gamma$-PGA by the addition of L-glutamate into the medium [14-16]. On the other hand, some other strains such as B. subtilis 5E, B. subtilis TAM-4, B. subtilis C10, B. licheiformis A35, and Bacillus sp. SAB-26 could produce $\gamma$-PGA through a de novo $\gamma$-PGA synthesis pathway [13]. $\gamma$-PGA is synthesized in a ribosome-independent manner, and then protein synthesis inhibitors like chloramphenicol have no inhibition effect on its production. Depending on the strains, $\gamma$-PGA is produced in different molecular weights ranging from 100 to $10,000 \mathrm{kDa}$ [1].

Although the microbial production of $\gamma$-PGA is well established, the production cost still remains high because of the cost of both raw materials and the recovery process. Generally, in the fermentation process, the substrate cost is very high, i.e. nearly $60 \%$ of the total production cost. Therefore, it is essential to focus on the development of a cost-effective alternative medium. It requires selection of carbon source, nitrogen source, and inorganic salts. Recently, many research groups have investigated the optimization of growth conditions to increase yield, manipulation of enantiomeric composition, and alteration of the molecular mass of the $\gamma$-PGA [17-20]. Medium components and fermentation conditions can be manipulated by conventional or statistical methods. The conventional method is a very tedious and time-consuming process where we can only study one variable at a time while keeping others at a fixed level. However, advanced statistical methods provide possibility of studying many variables at one time and of studying the interactions among the medium and fermentation factors, and it is also fast and reliable. This in turn reduces the total number of experiments and saves the cost of the nutrients $[20,21]$. Therefore, the aim of the present research is enhancement of $\gamma$-PGA production through the optimization of medium components by central composite design (CCD) for response surface methodology (RSM) using a newly isolated Bacillus sp. FBL-2.

\section{Materials and Methods}

\author{
Bacterial Strain and Culture Medium \\ Bacillus sp. FBL-2 KCTC 12962BP isolated from cheonggukjang,
}

a fermented soybean paste, was utilized for $\gamma$-PGA production. The 16S rRNA gene sequence of strain FBL-2 was submitted to the GenBank database (https://www.ncbi.nlm.nih.gov/genbank), under accession number LY513821. To preserve the culture, 50\% $(\mathrm{v} / \mathrm{v})$ glycerol as a cryoprotectant was added to the culture and then kept at $-70^{\circ} \mathrm{C}$ in a deep freezer until usage. The stock culture was activated by inoculation into the culture medium, followed by cultivation at $37^{\circ} \mathrm{C}$ on a shaking incubator (Vision Scientific Co., Korea) at $200 \mathrm{rpm}$.

The medium for growth and maintenance consisted of glucose $10.0 \mathrm{~g} / \mathrm{l}$, yeast extract $3.0 \mathrm{~g} / \mathrm{l}$, L-glutamic acid $20.0 \mathrm{~g} / \mathrm{l}, \mathrm{KH}_{2} \mathrm{PO}_{4}$ $1.0 \mathrm{~g} / \mathrm{l}$, and $\mathrm{MgSO}_{4} \cdot 7 \mathrm{H}_{2} \mathrm{O} 1.0 \mathrm{~g} / 1(\mathrm{pH}$ 7.0). The production medium was composed of glucose $10.0 \mathrm{~g} / \mathrm{l}$, yeast extract $4.0 \mathrm{~g} / \mathrm{l}$, L-glutamic acid $30.0 \mathrm{~g} / \mathrm{l}, \mathrm{KH}_{2} \mathrm{PO}_{4} 1.0 \mathrm{~g} / \mathrm{l}$, and $\mathrm{MgSO}_{4} \cdot 7 \mathrm{H}_{2} \mathrm{O} 1.0 \mathrm{~g} / \mathrm{l}$ ( $\mathrm{pH}$ 7.0). The composition and amount of production medium used were different depending on the experimental conditions. A detailed experimental condition of the production medium was given later.

\section{Fermentation}

The bacterial strain was cultured at $37^{\circ} \mathrm{C}$ for $24 \mathrm{~h}$ in the shaking incubator (Vision Scientific Co.) at $200 \mathrm{rpm}$ by inoculating $2 \mathrm{ml}$ of the stock culture into $100 \mathrm{ml}$ growth medium in a $250-\mathrm{ml}$ Erlenmeyer flask. The fermentation for $\gamma$-PGA production was carried out at $37^{\circ} \mathrm{C}$ for $12 \mathrm{~h}$ in the shaking incubator at $200 \mathrm{rpm}$ by inoculating $3.0 \%(\mathrm{v} / \mathrm{v})$ growth culture into $100 \mathrm{ml}$ production medium in a 250-ml Erlenmeyer flask.

To investigate the effect of carbon sources on $\gamma$-PGA production by Bacillus sp. FBL-2, the medium components except glucose in the production medium were kept the same as above. The carbon source, including glucose, lactose, fructose, sucrose, galactose, maltose, glycerol, and xylose was added to a $250 \mathrm{ml}$-Erlenmeyer flask at a concentration of $10 \mathrm{~g} / \mathrm{l}$, and the cells were inoculated and aerobically cultivated at $37^{\circ} \mathrm{C}$ for $12 \mathrm{~h}$ in the rotary shaker at $200 \mathrm{rpm}$. To investigate the effect of nitrogen sources on $\gamma$-PGA production by Bacillus sp. FBL-2, the medium components except yeast extract in the production medium were kept the same as above. The nitrogen source, including yeast extract, beef extract, malt extract, tryptone, peptone, urea, ammonium sulfate, ammonium chloride, and corn steep liquor was added to a $250 \mathrm{ml}-$ Erlenmeyer flask at a concentration of $4 \mathrm{~g} / \mathrm{l}$, and the cells were inoculated and aerobically cultured at $37^{\circ} \mathrm{C}$ for $12 \mathrm{~h}$ in the rotary shaker at $200 \mathrm{rpm}$.

\section{Statistical Experimental Design for Response Surface Methodology}

Reaction surface methodology (RSM) was carried out through the central composite design (CCD) to investigate which combination of key interactions and independent variables of $\gamma$ PGA production could lead to the maximum response value. RSM is a combination of statistical methods for selecting the optimum experimental conditions that require the minimum number of experiments. 


$$
x_{i}=\frac{X_{i}-X_{0}}{\Delta X_{i}}
$$

The experimental variables were coded by using the above equation, where $X_{i}$ is the actual value of the independent variable, $X_{0}$ is the independent variable value at the center point, $\Delta X_{i}$ is the step change value, and $x_{i}$ is the coded value of each independent variable.

In this study, the concentration of $\mathrm{KH}_{2} \mathrm{PO}_{4}$ and $\mathrm{MgSO}_{4} \cdot 7 \mathrm{H}_{2} \mathrm{O}$ in the production medium was kept at $1.0 \mathrm{~g} / \mathrm{l}$, and four important components such as sucrose, L-glutamic acid, yeast extract, and

Table 1. Central composite design matrix of four independent variables.

\begin{tabular}{|c|c|c|c|c|}
\hline \multirow[b]{2}{*}{$\begin{array}{c}\text { Run } \\
\text { number }\end{array}$} & \multicolumn{4}{|c|}{ Levels of independent variables } \\
\hline & $\begin{array}{l}\text { Sucrose } \\
\left(x_{1}, \mathrm{~g} / 1\right)\end{array}$ & $\begin{array}{c}\text { L-Glutamic } \\
\text { acid } \\
\left(x_{2}, \mathrm{~g} / \mathrm{l}\right)\end{array}$ & $\begin{array}{c}\text { Yeast } \\
\text { extract } \\
\left(x_{3}, \mathrm{~g} / \mathrm{l}\right) \\
\end{array}$ & $\begin{array}{c}\text { Citric } \\
\text { acid } \\
\left(x_{4}, \mathrm{~g} / \mathrm{l}\right)\end{array}$ \\
\hline 1 & 30 & 75 & 10 & 15 \\
\hline 2 & 70 & 75 & 10 & 15 \\
\hline 3 & 30 & 125 & 10 & 15 \\
\hline 4 & 70 & 125 & 10 & 15 \\
\hline 5 & 30 & 75 & 20 & 15 \\
\hline 6 & 70 & 75 & 20 & 15 \\
\hline 7 & 30 & 125 & 20 & 15 \\
\hline 8 & 70 & 125 & 20 & 15 \\
\hline 9 & 30 & 75 & 10 & 25 \\
\hline 10 & 70 & 75 & 10 & 25 \\
\hline 11 & 30 & 125 & 10 & 25 \\
\hline 12 & 70 & 125 & 10 & 25 \\
\hline 13 & 30 & 75 & 20 & 25 \\
\hline 14 & 70 & 75 & 20 & 25 \\
\hline 15 & 30 & 125 & 20 & 25 \\
\hline 16 & 70 & 125 & 20 & 25 \\
\hline 17 & 90 & 100 & 15 & 20 \\
\hline 18 & 10 & 100 & 15 & 20 \\
\hline 19 & 50 & 50 & 15 & 20 \\
\hline 20 & 50 & 150 & 15 & 20 \\
\hline 21 & 50 & 100 & 5 & 20 \\
\hline 22 & 50 & 100 & 25 & 20 \\
\hline 23 & 50 & 100 & 15 & 10 \\
\hline 24 & 50 & 100 & 15 & 30 \\
\hline 25 & 50 & 100 & 15 & 20 \\
\hline 26 & 50 & 100 & 15 & 20 \\
\hline 27 & 50 & 100 & 15 & 20 \\
\hline 28 & 50 & 100 & 15 & 20 \\
\hline 29 & 50 & 100 & 15 & 20 \\
\hline 30 & 50 & 100 & 15 & 20 \\
\hline
\end{tabular}

citric acid were used as the independent variables for the designed sets of experiment. As shown in Table 1, to investigate the nature of the response surface in the optimum region, a $2^{4}$ factorial CCD with eight axial points and six replicates of center points was used at five levels, resulting in the total number of 30 experiments.

To optimize the production of $\gamma$-PGA, the following secondorder polynomial equation was used for statistical analysis.

$$
y=b_{0}+\sum b_{i} x_{i}+\sum b_{i j} x_{i} x_{j}+\sum b_{i i} x_{i}^{2}
$$

where $y$ is a predicted value, $b_{0}$ is a constant, $b_{i}$ and $b_{i i}$ and $b_{i j}$ are first-order coefficients, second-order coefficients, and interaction coefficients, respectively. $x_{i}$ is the independent variable of $i, x_{i} x_{j}$ is the interaction between independent variables, and $x_{i}^{2}$ is the second order coefficient. The quality of fit of the model equation was described by the coefficient of determination, $R^{2}$, and the significance of statistics was determined by an F-test. The significance of the regression coefficients was investigated by a $t$ test. The computer software used was Design-Expert, version 9.0.0 by Stat-Ease, Inc. (USA).

\section{Analytical Methods}

The cell growth was monitored by measurement of optical density using a UV-1600 spectrophotometer (Shimadzu Co., Tokyo, Japan) at $660 \mathrm{~nm}$, which was then converted to dry cell weight (DCW, $g / 1)$ based on the liner relation of DCW and optical density. The viscosity of the culture broth containing $\gamma$-PGA was measured by DV2T digital rheometer equipped with a spindle CP-42 (Brookfield, Middleboro, MA, USA) at $25^{\circ} \mathrm{C}$ and $10 \mathrm{rpm}$ for $30 \mathrm{sec}$. The measured viscosity was corrected by silicon oil standards $\left(44.8 \mathrm{cP}\right.$ and $496 \mathrm{cP}$ at $\left.25^{\circ} \mathrm{C}\right)$.

$\gamma$-PGA was determined by alcohol precipitation according to the modified method reported by Kunioka and Goto [15]. The fermentation broth was diluted and centrifuged at 32,000 $\times g$ for $30 \mathrm{~min}$. The resulting supernatant was poured into 4 volumes of cold ethanol. The precipitate was collected and washed with ethanol, then dissolved and dialyzed against deionized water overnight. The dialyzed solution was centrifuged and the supernatant was lyophilized to prepare pure $\gamma$-PGA.

\section{Results and Discussion}

The eight different carbon sources and nine nitrogen sources were selected for screening and evaluating their potentiality in producing high quantity $\gamma$-PGA using the shake flask culture method. Among the various carbon sources evaluated, sucrose showed the highest levels of production of $\gamma$-PGA and DCW followed by glucose (Table 2). These results are in accordance with Shi et al. [22] where they examined 7 different carbon sources and found sucrose as the best with similar $\gamma$-PGA yield and DCW. 
Table 2. Effect of carbon sources on $\gamma$-PGA fermentation by Bacillus sp. FBL-2.

\begin{tabular}{lcccc}
\hline $\begin{array}{c}\text { Carbon } \\
\text { sources } \\
(10.0 \mathrm{~g} / \mathrm{l})\end{array}$ & $\begin{array}{c}\gamma \text {-PGA } \\
(\mathrm{g} / \mathrm{l})\end{array}$ & $\begin{array}{c}\text { Dry cell } \\
\text { weight } \\
(\mathrm{g} / \mathrm{l})\end{array}$ & $\begin{array}{c}\text { Viscosity } \\
(\mathrm{cP})\end{array}$ & $\begin{array}{c}\text { Productivity } \\
(\mathrm{g} / \mathrm{l} / \mathrm{h})\end{array}$ \\
\hline None & 0.46 & 0.99 & 1.70 & 0.038 \\
Lactose & 0.63 & 1.04 & 2.33 & 0.053 \\
Fructose & 3.63 & 1.49 & 17.13 & 0.303 \\
Sucrose & 4.60 & 1.81 & 20.94 & 0.383 \\
Galactose & 1.25 & 1.09 & 4.45 & 0.104 \\
Maltose & 2.86 & 1.17 & 12.79 & 0.238 \\
Glucose & 3.96 & 1.74 & 19.11 & 0.330 \\
Glycerol & 0.86 & 0.63 & 3.91 & 0.072 \\
Xylose & 0.63 & 0.86 & 2.14 & 0.053 \\
\hline
\end{tabular}

However, some of the previous reports concluded that citric acid and glycerol were better carbon sources for the production of $\gamma$-PGA than glucose or sucrose [20, 23, 24]. In our present work, the results showed that sucrose was the best carbon source for $\gamma$-PGA accumulation and cell growth, which suggests that the metabolic pathways in Bacillus sp. FBL-2 might be different from other glutamic acid-dependent strains for $\gamma$-PGA production. In general, glucose is the preferable carbon source for the production of $\gamma$-PGA which mostly utilizes the TCA cycle. It can be also concluded that Bacillus sp. FBL-2 utilizes the general TCA cycle for $\gamma$-PGA production after hydrolyzing the sucrose to glucose and fructose. Anju et al. [25] studied the utilization of lignocellulosic renewable resources for the production of $\gamma$-PGA and reported that the highest $\gamma$-PGA yield was from rice straw hydrolyzates, where glucose was the main carbon source.

In nitrogen sources investigated, yeast extract showed the highest production of $\gamma$-PGA and peptone resulted in the highest cell growth (Table 3). The results indicated that inorganic nitrogen sources such as ammonium sulfate and ammonium chloride could not support $\gamma$-PGA synthesis and cell growth. Shi et al. [22] have screened 7 different nitrogen sources and reported that incorporation of organic nitrogen sources increased the yields of $\gamma$-PGA and no inorganic nitrogen sources had a significant effect. At the same time, many of the researchers used inorganic nitrogen sources for $\gamma$-PGA production [23, 24]. Goto and Kunioka [24] have observed the enhancement of $\gamma$-PGA by the addition of ammonium sulfate $(5 \mathrm{~g} / \mathrm{l})$ and suggested that the free amino group was necessary for $\gamma$-PGA production and was readily available from inorganic nitrogen salts such as ammonium sulfate. According to the above reports, it can be concluded that the selection of nitrogen source is purely dependent on the microbial strain and there is no universal/single suitable source.

Based on the primary screening process, sucrose $\left(x_{1}\right)$, Lglutamic acid $\left(x_{2}\right)$, yeast extract $\left(x_{3}\right)$, and citric acid $\left(x_{4}\right)$ were selected as the independent variables for further optimization by RSM. A central composite factorial design of 30 experiments was conducted to examine the combined effect of these medium components on $\gamma$-PGA production. The $P$-values were used as the tool to check the significance of each variable, which, in turn, are necessary to understand the pattern of the mutual interactions between the selected variables. The ANOVA (analysis of variance) result of the optimization study indicated that the model terms, $x_{1}, x_{2}, x_{4}, x_{2} x_{3}, x_{2} x_{4}, x_{3} x_{4}, x_{1}^{2}$, and $x_{2}^{2}$, were significant $(p<0.05)$ (Table 4). The lower the $P$-value is, the more significant the corresponding variable. The variables and the corresponding $P$-values suggest that among the variables tested in the present study, sucrose $\left(x_{1}\right), \mathrm{L}-$ glutamic acid $\left(x_{2}\right)$, and citric acid $\left(x_{4}\right)$ independently show their significance. The interaction effects between L-

Table 3. Effect of nitrogen sources on $\gamma$-PGA fermentation by Bacillus sp. FBL-2.

\begin{tabular}{lccc}
\hline Nitrogen sources $(4.0 \mathrm{~g} / \mathrm{l})$ & $\gamma$-PGA $(\mathrm{g} / \mathrm{l})$ & Dry cell weight $(\mathrm{g} / \mathrm{l})$ & Viscosity $(\mathrm{cP})$ \\
\hline None & 1.63 & 0.76 & 1.83 \\
Beef extract & 3.98 & 1.72 & 0.136 \\
Yeast extract & 4.50 & 1.85 & 0.332 \\
Malt extract & 1.74 & 0.83 & 19.64 \\
Tryptone & 4.39 & 1.51 & 2.23 \\
Peptone & 3.83 & 1.33 & 19.33 \\
Urea & 0.00 & 0.22 & 23.38 \\
Ammonium sulfate & 2.63 & 0.145 \\
Ammonium chloride & 2.29 & 0.77 & 1.23 \\
Corn steep liquor & 1.67 & 0.80 & 0.319 \\
\end{tabular}


Table 4. Analysis of variance (ANOVA) for the response surface quadratic model.

\begin{tabular}{|c|c|c|c|c|c|}
\hline Source & Sum of squares & Degree of freedom & Mean square & $F$-value & $\begin{array}{l}p \text {-value } \\
\text { Prob. }>F\end{array}$ \\
\hline Model & $2,233.08$ & 14 & 159.51 & 122.44 & $<0.0001$ \\
\hline$x_{1}$ & 285.94 & 1 & 285.94 & 219.49 & $<0.0001$ \\
\hline$x_{2}$ & 69.56 & 1 & 69.56 & 53.4 & $<0.0001$ \\
\hline$x_{3}$ & 8.32 & 1 & 8.32 & 6.39 & 0.0232 \\
\hline$x_{4}$ & 779.53 & 1 & 779.53 & 598.38 & $<0.0001$ \\
\hline$x_{1} x_{2}$ & 0.61 & 1 & 0.61 & 0.47 & 0.5034 \\
\hline$x_{1} x_{3}$ & 1.45 & 1 & 1.45 & 1.11 & 0.3088 \\
\hline$x_{1} x_{4}$ & 0.3 & 1 & 0.3 & 0.23 & 0.6399 \\
\hline$x_{2} x_{3}$ & 17.98 & 1 & 17.98 & 13.8 & 0.0021 \\
\hline$x_{2} x_{4}$ & 330.42 & 1 & 330.42 & 253.64 & $<0.0001$ \\
\hline$x_{3} x_{4}$ & 58.26 & 1 & 58.26 & 44.72 & $<0.0001$ \\
\hline$x_{1}^{2}$ & 382.78 & 1 & 382.78 & 293.83 & $<0.0001$ \\
\hline$x_{2}^{2}$ & 326.49 & 1 & 326.49 & 250.62 & $<0.0001$ \\
\hline$x_{3}^{2}$ & 8.97 & 1 & 8.97 & 6.89 & 0.0191 \\
\hline$x_{4}^{2}$ & 8.05 & 1 & 8.05 & 6.18 & 0.0252 \\
\hline Residual & 19.54 & 15 & 1.3 & & \\
\hline Lack of fit & 17.87 & 10 & 1.79 & 5.36 & 0.0389 \\
\hline Pure error & 1.67 & 5 & 0.33 & & \\
\hline Corrected total & $2,252.62$ & 29 & & & \\
\hline
\end{tabular}

$R^{2}=0.9913 ;$ adjusted $R^{2}=0.9832 ;$ adequately precise $=43.877 ; \mathrm{CV}=4.94 \%$.

glutamic acid $\left(x_{2}\right)$ and yeast extract $\left(x_{3}\right)$, L-glutamic acid $\left(x_{2}\right)$ and citric acid $\left(x_{4}\right)$, and yeast extract $\left(x_{3}\right)$ and citric acid $\left(x_{4}\right)$ also showed good significance. Other interactions were found to be insignificant. The model $F$-value was 122.44 , and the $F$-value for lack of fit was 5.52. The high $F$-value and non-significant lack of fit indicate that the model is a good fit. The $p$-values for the model $(<0.0001)$ and for lack of fit (0.0389) suggested that the obtained experimental data was a good fit with the model. The regression equation coefficients were calculated and the data were fitted to a second-order polynomial equation. The response, $\gamma$-PGA production ( $y$ ) by Bacillus sp. FBL-2, can be expressed in terms of the following regression equation:

$y=28.87+3.45 x_{1}+1.7 x_{2}-0.59 x_{3}-5.70 x_{4}-0.20 x_{1} x_{2}-$ $0.30 x_{1} x_{3}-0.14 x_{1} x_{4}+1.06 x_{2} x_{3}-4.54 x_{2} x_{4}-1.91 x_{3} x_{4}-3.74 x_{1}^{2}-$ $3.45 x_{2}^{2}-0.57 x_{3}^{2}+0.54 x_{4}^{2}$

The regression equation obtained from the ANOVA showed that the $R^{2}$ (multiple correlation coefficient) was 0.9913, where $R^{2}>0.75$ usually indicates fitness of the model. This is an estimate of the fraction of overall variation in the data accounted by the model, and thus the model is capable of explaining $99.13 \%$ of the variation in response. The 'adjusted $R^{2 \prime}$ is 0.9832 , and this result indicates that the model should be acceptable. For a good statistical model, the $R^{2}$ value should be in the range of 0 1.0 , and the nearer to 1.0 the value is, the more fit the model is deemed to be. The 'adequate precision value' of the present model was 29.50, and this suggests that the model can be used to navigate the design space. The 'adequate

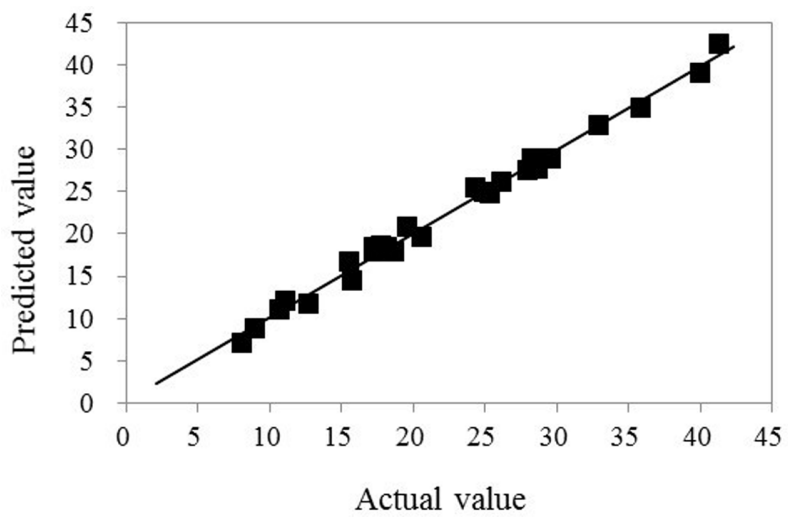

Fig. 1. Correlation of predicted values versus experimental values of the response surface methodological model developed by central composite design. 
precision value' is an index of the signal-to-noise ratio, and values of higher than 4 are essential prerequisites for a model to be a good fit. As shown in Fig. 1, the correlation between predicted and observed values showed very good linearity.

In order to determine the optimal levels of each variable for maximum $\gamma$-PGA production, 3-dimensional response surface plots were constructed by plotting the response on the z-axis against any two independent variables, while maintaining other variables at their optimal levels. As shown in Figs. 2A-2F, $\gamma$-PGA production could not increase further with increasing sucrose or L-glutamic acid
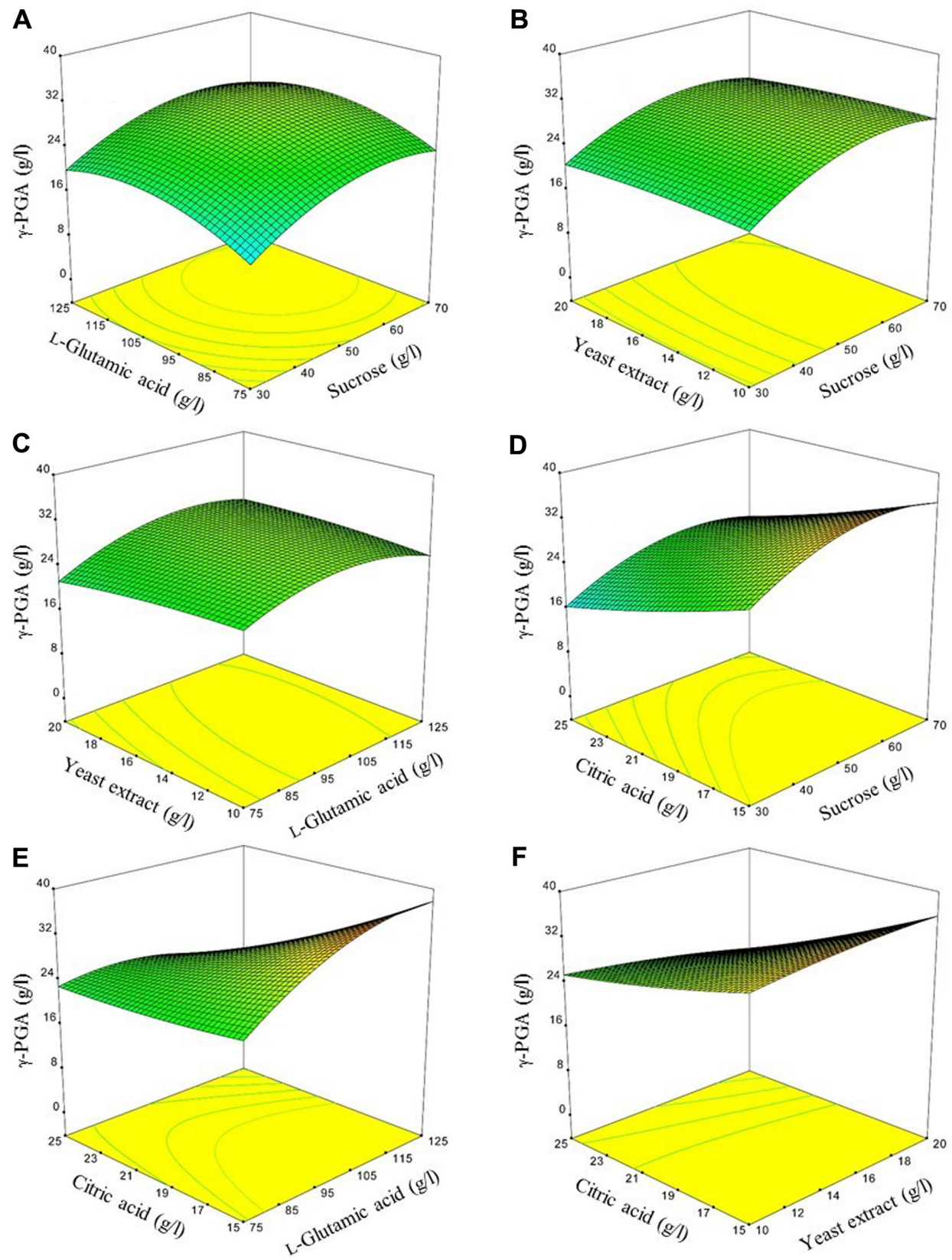

Fig. 2. Response surface and contour plots of poly( $\gamma$-glutamic acid) production by Bacillus sp. FBL-2 showing the mutual interactions of independent parameters.

Other variables except for two variables in each figure were maintained at center point level. (A), sucrose and L-glutamic acid; (B), sucrose and yeast extract; (C), sucrose and citric acid; (D), L-glutamic acid and yeast extract; (E), L-glutamic acid and citric acid; (F), yeast extract and citric acid. 
and showed very good center point (optimum levels). From the central point of the contour plot, the optimal process parameters were identified. A linear increase in $\gamma$ PGA secretion was observed when the citric acid and yeast extract concentrations were increased, and no concomitant decline in $\gamma$-PGA production was observed. A similar profile was observed in Fig. 2E with citric acid and Lglutamic acid concentration. The experimental data were fitted into the aforementioned equation, and the optimum levels of each variable were determined to be as follows: sucrose $51.73 \mathrm{~g} / \mathrm{l}$, L-glutamic acid $105.30 \mathrm{~g} / \mathrm{l}$, yeast extract $13.25 \mathrm{~g} / \mathrm{l}$, and citric acid $10.04 \mathrm{~g} / 1$.

Fig. 3 shows the profiles of cell growth, $\gamma$-PGA production, viscosity, and productivity when Bacillus sp. FBL-2 was cultured under the optimized medium factors, and it was observed the cells were very quickly grown within $12 \mathrm{~h}$ of incubation period with maximum DCW of $1.28 \mathrm{~g} / \mathrm{l}$. There was no decline in the growth after $12 \mathrm{~h}$, which suggests the optimized medium with sufficient amounts of L-glutamic acid and sucrose. The experiment was conducted for only $12 \mathrm{~h}$ and maximum production of $44.04 \mathrm{~g} / 1 \gamma$-PGA was obtained with $19.59 \mathrm{cP}$ viscosity. This amount of $\gamma$-PGA production under the optimized condition was almost similar to the predicted $\gamma$-PGA production (43.52 g/l). $\gamma$ PGA production was not considerably increased after $12 \mathrm{~h}$ probably because this fermentation was performed under the flask cultivation (data not shown). On the other hand, the maximum $\gamma$-PGA production using the non-optimized medium was only $3.96 \mathrm{~g} / \mathrm{l}$ with $19.11 \mathrm{cP}$ viscosity. From the above results, it can be concluded that a significant improvement (11.12-fold) in the production of $\gamma$-PGA was achieved using sucrose and yeast extract as carbon and nitrogen sources within a lesser incubation period (Table 5). The close relationship between the predicted and experimental response values from the investigation demonstrated the validity and acceptability of the statistical model for the optimization of the medium nutrients, allowing for maximum yields.

The present investigation shows that the amount of sucrose and L-glutamic acid in the culture medium are important for high $\gamma$-PGA productivity in Bacillus sp. FBL2. $\gamma$-PGA synthesis in B. subtilis is an ATP-consuming
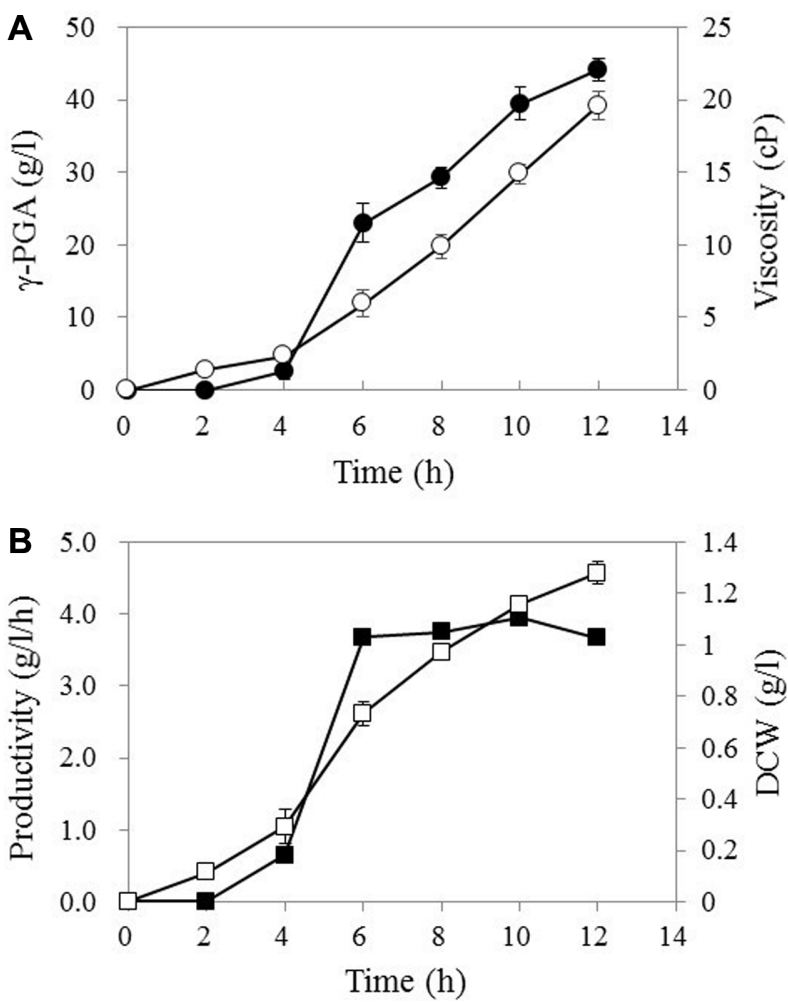

Fig. 3. Profiles of poly( $\gamma$-glutamic acid) production, viscosity, cell growth, and volumetric productivity in shake flask experiments using the optimized media.

Symbols: - -, $\gamma$-PGA; - $\bigcirc-$, viscosity; - - -, DCW (dry cell weight); $-\square$-, productivity.

bioprocess. The rate of conversion from L-glutamic acid to $\gamma$-PGA should be considered very important for reducing the cost of large-scale fermentation-based production of $\gamma$ PGA [26]. It is very important to note that the nitrogen source, yeast extract concentration $(10 \mathrm{~g} / \mathrm{l})$ used in the present study is low when compared to previous studies $[22,27,28]$. It is very essential to use less nitrogen source because it is very expensive and it will be $20-30 \%$ of the total medium cost. $\gamma$-PGA has recently been produced on a large scale using several bacterial strains. Table 6 shows the comparison of $\gamma$-PGA fermentation by Bacillus sp. FBL-2 with other literature reported previously. The highest $\gamma$ -

Table 5. Poly( $\gamma$-glutamic acid) fermentation results of Bacillus sp. FBL-2 cultured by using non-optimized and optimized medium components.

\begin{tabular}{lccccc}
\hline & $\gamma$-PGA $(\mathrm{g} / \mathrm{l})$ & DCW $(\mathrm{g} / \mathrm{l})$ & Viscosity $(\mathrm{cP})$ & Productivity $\left(\mathrm{g} \cdot \mathrm{l}^{-1} \cdot \mathrm{h}^{-1}\right)$ & Fold production \\
\hline Non-optimized & $3.96 \pm 0.67$ & $1.74 \pm 0.06$ & $19.11 \pm 1.14$ & 0.33 & 1.0 \\
Optimized & $44.04 \pm 1.54$ & $1.28 \pm 0.04$ & $19.59 \pm 0.95$ & 3.67 & 11.12 \\
\hline
\end{tabular}


Table 6. Poly( $\gamma$-glutamic acid) fermentation results of Bacillus sp. FBL-2 and other microorganisms reported previously.

\begin{tabular}{|c|c|c|c|c|c|}
\hline Strains & Fermentation medium components & Culture conditions & $\begin{array}{c}\gamma \text {-PGA } \\
(\mathrm{g} / \mathrm{l})\end{array}$ & $\begin{array}{l}\text { Productivity } \\
\left(\mathrm{g} \cdot \mathrm{l}^{-1} \cdot \mathrm{h}^{-1}\right)\end{array}$ & Ref. \\
\hline B. subtilis ZJU-7 & $\begin{array}{l}\text { Sucrose } 60 \mathrm{~g} / \mathrm{l} \text {, tryptone } 60 \mathrm{~g} / \mathrm{l} \text {, L-glutamic acid } 80 \mathrm{~g} / \mathrm{l} \text {, } \\
\mathrm{NaCl} 10 \mathrm{~g} / 1\end{array}$ & $\begin{array}{l}\text { 500-ml flask, } 200 \mathrm{rpm}, 37^{\circ} \mathrm{C} \text {, } \\
\text { initial } \mathrm{pH} 7.0\end{array}$ & 54.4 & 2.267 & 22 \\
\hline $\begin{array}{l}\text { B. methylotrophicus } \\
\text { SK19.001 }\end{array}$ & Glycerol $30 \mathrm{~g} / 1$, peptone $50 \mathrm{~g} / 1$, sodium citrate $15 \mathrm{~g} / 1$ & $\begin{array}{l}\text { 250-ml flask, } 200 \mathrm{rpm}, 30^{\circ} \mathrm{C} \text {, } \\
\text { initial } \mathrm{pH} 7.2\end{array}$ & 33.84 & 0.940 & 27 \\
\hline $\begin{array}{l}\text { B. licheniformis } \\
\text { NCIM } 2324\end{array}$ & $\begin{array}{l}\text { Glycerol } 62.4 \mathrm{~g} / \mathrm{l} \text {, L-glutamic acid } 20 \mathrm{~g} / \mathrm{l} \text {, citric acid } \\
15.2 \mathrm{~g} / 1,\left(\mathrm{NH}_{4}\right)_{2} \mathrm{SO}_{4} 8 \mathrm{~g} / 1, \mathrm{~K}_{2} \mathrm{HPO}_{4} 1 \mathrm{~g} / 1, \mathrm{MgSO}_{4} \cdot 7 \mathrm{H}_{2} \mathrm{O} \\
0.5 \mathrm{~g} / \mathrm{l}, \mathrm{MnSO}_{4} \cdot 7 \mathrm{H}_{2} \mathrm{O} 0.05 \mathrm{~g} / 1, \mathrm{CaCl}_{2} \cdot 2 \mathrm{H}_{2} \mathrm{O} 0.2 \mathrm{~g} / 1\end{array}$ & $\begin{array}{l}250-\mathrm{ml} \text { flask, } 200 \mathrm{rpm}, 37^{\circ} \mathrm{C} \text {, } \\
\text { initial } \mathrm{pH} 6.5\end{array}$ & 35.75 & 0.331 & 29 \\
\hline $\begin{array}{l}\text { B. licheniformis } \\
\text { SAB-26 }\end{array}$ & $\begin{array}{l}\text { Glucose } 20 \mathrm{~g} / \mathrm{l} \text {, casein hydrolysate } 8 \mathrm{~g} / \mathrm{l},\left(\mathrm{NH}_{4}\right)_{2} \mathrm{SO}_{4} \\
2 \mathrm{~g} / 1, \mathrm{~K}_{2} \mathrm{HPO}_{4} 5 \mathrm{~g} / 1, \mathrm{KH}_{2} \mathrm{PO}_{4} 5 \mathrm{~g} / 1\end{array}$ & $\begin{array}{l}\text { 250-ml flask, } 200 \mathrm{rpm}, 37^{\circ} \mathrm{C} \text {, } \\
\text { initial } \mathrm{pH} 7.0\end{array}$ & 33.5 & 2.792 & 30 \\
\hline $\begin{array}{l}\text { B. licheniformis } \\
\text { ATCC } 9945 a\end{array}$ & $\begin{array}{l}\text { Glycerol } 80 \mathrm{~g} / \mathrm{l} \text {, citric acid } 12 \mathrm{~g} / \mathrm{l} \text {, L-glutamate acid } \\
20 \mathrm{~g} / \mathrm{l}, \mathrm{NH}_{4} \mathrm{Cl} 7 \mathrm{~g} / \mathrm{l}, \mathrm{K}_{2} \mathrm{HPO}_{4} 0.5 \mathrm{~g} / \mathrm{l}, \mathrm{MgSO}_{4} \cdot 7 \mathrm{H}_{2} \mathrm{O} \\
0.5 \mathrm{~g} / 1, \mathrm{MnSO}_{4} \cdot \mathrm{H}_{2} \mathrm{O} 0.104 \mathrm{~g} / \mathrm{l}, \mathrm{CaCl}_{2} \cdot 2 \mathrm{H}_{2} \mathrm{O} 0.15 \mathrm{~g} / 1 \\
\mathrm{FeCl}_{3} \cdot 6 \mathrm{H}_{2} \mathrm{O} 0.04 \mathrm{~g} / 1\end{array}$ & $\begin{array}{l}\text { 300-ml flask, } 110 \mathrm{rpm}, 37^{\circ} \mathrm{C} \text {, } \\
\text { initial } \mathrm{pH} 6.5\end{array}$ & 34.93 & 0.364 & 32 \\
\hline $\begin{array}{l}\text { B. licheniformis } \\
\mathrm{WX}-02\end{array}$ & $\begin{array}{l}\text { Glucose } 80 \mathrm{~g} / \mathrm{l} \text {, } \mathrm{L} \text {-glutamic acid } 30 \mathrm{~g} / \mathrm{l} \text {, sodium citrate, } \\
\text { sodium nitrate } 10 \mathrm{~g} / \mathrm{l}, \mathrm{NH}_{4} \mathrm{Cl} 8 \mathrm{~g} / 1, \mathrm{CaCl}_{2} 1 \mathrm{~g} / \mathrm{l} \text {, } \\
\mathrm{K}_{2} \mathrm{HPO}_{4} \cdot 6 \mathrm{H}_{2} \mathrm{O} 1 \mathrm{~g} / \mathrm{l}, \mathrm{MgSO}_{4} \cdot 7 \mathrm{H}_{2} \mathrm{O} 1 \mathrm{~g} / 1, \mathrm{ZnSO}_{4} \cdot 7 \mathrm{H}_{2} \mathrm{O} \\
1 \mathrm{~g} / \mathrm{l}, \mathrm{MnSO}_{4} \cdot 7 \mathrm{H}_{2} \mathrm{O} 0.15 \mathrm{~g} / 1\end{array}$ & $\begin{array}{l}\text { 250-ml flask, } 180 \mathrm{rpm}, 37^{\circ} \mathrm{C} \text {, } \\
\text { initial } \mathrm{pH} 7.2\end{array}$ & 39.96 & 1.11 & 33 \\
\hline Bacillus sp. FBL-2 & $\begin{array}{l}\text { Sucrose } 51.73 \mathrm{~g} / \mathrm{l} \text {, L-glutamic acid } 105.23 \mathrm{~g} / \mathrm{l} \text {, yeast } \\
\text { extract } 13.25 \mathrm{~g} / \mathrm{l} \text {, citric acid } 10.04 \mathrm{~g} / 1, \mathrm{~K}_{2} \mathrm{HPO}_{4} 1.0 \mathrm{~g} / \mathrm{l} \text {, } \\
\mathrm{MgSO}_{4} \cdot 7 \mathrm{H}_{2} \mathrm{O} 1.0 \mathrm{~g} / 1\end{array}$ & $\begin{array}{l}\text { 250-ml flask, } 200 \mathrm{rpm}, 37^{\circ} \mathrm{C} \text {, } \\
\text { initial } \mathrm{pH} 7.0\end{array}$ & 44.04 & 3.67 & $\begin{array}{l}\text { This } \\
\text { study }\end{array}$ \\
\hline
\end{tabular}

PGA productivity reported by Shi et al. [22] was $2.267 \mathrm{~g} / 1 / \mathrm{h}$ (54.4 g/1 $\gamma$-PGA) using the B. subtilis ZJU-7 cultivated at $37^{\circ} \mathrm{C}$ for $24 \mathrm{~h}$. Bajaj et al. [29] reported a maximum $\gamma$-PGA production of $35.75 \mathrm{~g} / 1$ using B. licheniformis NCIM2324. Soliman et al. [30] reported a maximum $\gamma$-PGA production of $33.5 \mathrm{~g} / 1$ using Bacillus sp. SAB-26, and Cao et al. [31] reported a much lower amount of $\gamma$-PGA (4.36 g/l). B. licheniformis ATCC 9945a produced $34.93 \mathrm{~g} / 1$ of $\gamma$-PGA but the volumetric productivity was only $0.64 \mathrm{~g} / 1 / \mathrm{h}$ [32]. Cai et al. [33] reported $1.11 \mathrm{~g} / 1 / \mathrm{h}$ of $\gamma$-PGA productivity by flask fermentation of $B$. licheniformis WX-02. As shown in Table 6, Bacillus sp. FBL-2 could produce a high amount of $\gamma$-PGA with the highest volumetric productivity even though the compositions of production medium were simple compared with the other investigations. Therefore, compared with the strains in Table 6, Bacillus sp. FBL-2 has some advantages such as high productivity $\left(3.67 \mathrm{~g} \cdot \mathrm{l}^{-1} \cdot \mathrm{h}^{-1}\right)$, short incubation period $(12 \mathrm{~h})$, and utilization of less nitrogen source $(10 \mathrm{~g} / 1)$. To the best of our knowledge, the $\gamma$-PGA productivity reported in the present study is highest in the literature. The findings of this study indicate that media optimization and the use of Bacillus sp. FBL-2 organisms have significant scope for use in the industrial production of $\gamma$-PGA. In addition, the results presented here could be efficiently used in the area of $\gamma$-PGA production from inexpensive bioresources such as agricultural residues or food wastes [34].

This study was conducted in an attempt to optimize medium composition for maximum $\gamma$-PGA production. The eight carbon sources and seven nitrogen sources were screened, and sucrose and yeast extract were selected as carbon and nitrogen sources, respectively, based on the preliminary experiments. In order to optimize low-cost fermentation medium with precursors, such as L-glutamic acid and citric acid for $\gamma$-PGA production, RSM study was carried out using the screened variables. The most significant medium components appear to be sucrose $51.73 \mathrm{~g} / \mathrm{l}$, L-glutamic acid $105.30 \mathrm{~g} / \mathrm{l}$, yeast extract $13.25 \mathrm{~g} / \mathrm{l}$, and citric acid $10.04 \mathrm{~g} / \mathrm{l}$. The maximum $\gamma$-PGA concentration $(44.04 \mathrm{~g} / \mathrm{l})$ was obtained from this study with a much shorter incubation period $(12 \mathrm{~h})$ at $37^{\circ} \mathrm{C}$. As a result, the $\gamma$-PGA productivity could reach to $3.67 \mathrm{~g} \cdot \mathrm{l}^{-1} \cdot \mathrm{h}^{-1}$. This represents an 11.12-fold enhancement over the productivity observed with non-optimized medium. Thus, the statistical methods (RSM) may be effective for optimizing bioprocessing conditions for developing lowcost, large-scale methods of producing this important $\gamma$ PGA biomaterial in the future. 


\section{Acknowledgments}

This research was supported by the Basic Science Research Program through the National Research Foundation of Korea (NRF) funded by the Ministry of Education (2017R1D1A1B03032906). This work was also supported by the 2017 Yeungnam University Research Grant (217A061045).

\section{Conflict of Interest}

The authors have no financial conflicts of interest to declare.

\section{References}

1. Shih IL, Van YT. 2001. The production of poly( $\gamma$-glutamic acid) from microorganisms and its various applications. Bioresour. Technol. 79: 207-225.

2. Buescher JM, Margaritis AM. 2007. Microbial biosynthesis of polyglutamic acid biopolymer and applications in the biopharmaceutical, biomedical, and food industries. Crit. Rev. Biotechnol. 27: 1-19.

3. Akagi T, Baba M, Akashi M. 2007. Preparation of nanoparticles by the self-organization of polymers consisting of hydrophobic and hydrophilic segments: potential applications. Polymer 48: 6729-6747.

4. Li C. 2002. Poly(L-glutamic acid)-anticancer drug conjugates. Adv. Drug Deliv. Rev. 54: 695-713.

5. Matsuo K, Koizumi H, Akashi M, Nakagawa S, Fujita T, Yamamoto A, et al. 2011. Intranasal immunization with poly $(\gamma$-glutamic acid) nanoparticles entrapping antigenic proteins can induce potent tumor immunity. J. Control. Release 152: 310-316.

6. Tanimoto H, Fox T, Eagles J, Satoh H, Nozava H, Okiyama A, et al. 2007. Acute effect of poly( $\gamma$-glutamic acid) on calcium absorption in post-menopausal women. J. Am. Coll. Nutr. 26: 645-649.

7. Shih IL, Van YT, Sau YY. 2003. Antifreeze activities of poly( $\gamma$-glutamic acid) produced by Bacillus licheniformis. Biotechnol. Lett. 25: 1709-1712.

8. Bhat AR, Irorere VU, Bartlett T, Hill D, Kedia G, Morris MR, et al. 2013. Bacillus subtilis natto: a non-toxic source of poly $(\gamma$-glutamic acid $)$ that could be used as a cryoprotectant for probiotic bacteria. AMB Express 3: 36.

9. Lee CY, Kuo MI. 2011. Effect of $\gamma$-polyglutamate on the rheological properties and microstructure of tofu. Food Hydrocoll. 25: 1034-1040.

10. Zheng H, Gao Z, Yin J, Tang X, Ji X, Huang H. 2012. Harvesting of microalgae by flocculation with poly $(\gamma-$ glutamic acid). Bioresour. Technol. 112: 212-220.
11. Wang F, Zhao J, Wei X, Huo F, Li W, Hu Q, Liu H. 2014. Adsorption of rare earths (III) by calcium alginate-poly glutamic acid hybrid gels. J. Chem. Technol. Biotechnol. 89: 969-977.

12. Candela T, Fouet A. 2006. Poly-gamma-glutamate in bacteria. Mol. Microbiol. 60: 1091-1098.

13. Ashiuchi M. 2010. Occurrence and biosynthetic mechanism of poly-gamma-glutamic acid, pp. 77-93. In Hamano Y (ed.), Amino-Acid Homopolymers Occurring in Nature, Springer, New York, N.Y.

14. Birrer GA, Cromwick AM, Gross RA. 1994. $\gamma$-Poly(glutamic acid) formation by Bacillus licheniformis 9945A: physiological and biochemical studies. Int. J. Biol. Macromol. 16: 265-275.

15. Kunioka M, Goto A. 1994. Biosynthesis of poly( $\gamma$-glutamic acid) from L-glutamic acid, citric acid, and ammonium sulfate in Bacillus subtilis IFO3335. Appl. Microbiol. Biotechnol. 40: $867-872$.

16. Jeong JH, Kim JN, Wee YJ and Ryu HW. 2010. The statistically optimized production of poly( $\gamma$-giutamic acid) by batch fermentation of a newly isolated Bacillus subtilis RKY3. Bioresour. Technol. 101: 4533-4539.

17. Cromwick AM, Birrer GA, Gross RA. 1996. Effects of $\mathrm{pH}$ and aeration on $\gamma$-poly(glutamic acid) formation by Bacillus licheniformis in controlled batch fermentor cultures. Biotechnol. Bioeng. 50: 222-227.

18. Jung DH, Jung S, Yun, JS, Kim JN, Wee YJ, Jang HG, et al. 2005. Influences of cultural medium component on the production of poly( $\gamma$-glutamic acid) by Bacillus sp. RKY3. Biotechnol. Bioprocess Eng. 10: 289-295.

19. Chen X, Chen S, Sun M, Yu Z. 2005. Medium optimization by response surface methodology for poly- $\gamma$-glutamic acid production using dairy manure as the basis of a solid substrate. Appl. Microbiol. Biotechnol. 69: 390-396.

20. Bajaj B, Lele SS, Singhal RS. 2009. A statistical approach to optimization of fermentative production of poly $(\gamma$-glutamic acid) from Bacillus licheniformis NCIM 2324. Bioresour. Technol. 100: 826-832.

21. Reddy LVA, Wee YJ, Yun JS, Ryu HW. 2008. Optimization of alkaline protease production by batch culture of Bacillus sp. RKY3 through Plackett-Burman and response surface methodological approaches. Bioresour. Technol. 99: 2242-2249.

22. Shi F, Xu Z, Cen P. 2006. Efficient production of poly- $\gamma-$ glutamic acid by Bacillus subtilis ZJU-7. Appl. Biochem. Biotechnol. 133: 271-281.

23. Du G, Yang G, Qu Y, Chen J, Lun S. 2005. Effects of glycerol on the production of poly $(\gamma$-glutamic acid $)$ by Bacillus licheniformis. Process Biochem. 40: 2143-2147.

24. Goto A, Kunioka M. 1992. Biosynthesis and hydrolysis of poly-( $\gamma$-glutamic acid) from Bacillus subtilis IFO3335. Biosci. Biotechnol. Biochem. 56: 1031-1035.

25. Anju AJ, Binod P, Pandey A. 2017. Production and characterization of microbial poly- $\gamma$-glutamic acid from renewable resources. Indian J. Exp. Biol. 55: 405-410. 
26. Ashiuchi M, Tani K, Soda K, Misono H. 1998. Properties of glutamate racemase from Bacillus subtilis IFO 3336 producing poly- $\gamma$-glutamate. J. Biochem. 123:1156-1163.

27. Peng Y, Jiang B, Zhang T, Mu W, Miao M, Hua Y. 2015. High-level production of poly( $\gamma$-glutamic acid) by a newly isolated glutamate-independent strain, Bacillus methylotrophicus. Process Biochem. 50: 329-335.

28. Tork SE, Aly MM, Alakilli SY, Al-Seeni MN. 2015. Purification and characterization of gamma poly glutamic acid from newly Bacillus licheniformis NRC20. Int. J. Biol. Macromol. 74: 382-391.

29. Bajaj IB, Singhal RS. 2009. Enhanced production of poly $(\gamma-$ glutamic acid) from Bacillus licheniformis NCIM 2324 by using metabolic precursors. Appl. Biochem. Biotechnol. 159: 133-141.

30. Soliman NA, Berekaa MM, Abdel-Fattah YR. 2005. Polyglutamic acid (PGA) production by Bacillus sp. SAB-26: application of Plackett-Burman experimental design to evaluate culture requirements. Appl. Microbiol. Biotechnol. 69: 259-267.

31. Cao M, Geng W, Liu L, Song C, Xie H, Guo W, et al. 2011. Glutamic acid independent production of poly- $\gamma$-glutamic acid by Bacillus amyloliquefaciens LL3 and cloning of pgsBCA genes. Bioresour. Technol. 102: 4251-4257.

32. Feng J, Shi Q, Zhou G, Wang L, Chen A, Xie X, et al. 2017. Improved production of poly- $\gamma$-glutamic acid with low molecular weight under high ferric ion concentration stress in Bacillus licheniformis ATCC 9945a. Process Biochem. 56: 30-36.

33. Cai D, Hu S, Chen Y, Liu L, Yang S, Ma X, et al. 2018. Enhanced production of poly- $\gamma$-glutamic acid by overexpression of the global anaerobic regulator Fnr in Bacillus licheniformis WX-02. Appl. Biochem. Biotechnol. 185: 959-970.

34. Reddy LV, Kim YM, Yun JS, Ryu HW, Wee YJ. 2016. LLactic acid production by combined utilization of agricultural bioresources as renewable and economical substrates through batch and repeated-batch fermentation of Enterococcus faecalis RKY1. Bioresour. Technol. 209: 187-194. 